\title{
A theoretical model of transformational leadership and knowledge creation: The role of open-mindedness norms and leader-member exchange
}

\begin{abstract}
Considerable research attention has been devoted to understanding the importance of knowledge creation in organisations over the last decade. Research suggests that leadership plays an important role in knowledge creation processes. Nonetheless, there is an important omission in knowledge creation research; namely, what are the underlying processes that underpin the implications of leadership for knowledge creation? This article aims to develop a theoretical model of leadership and knowledge creation by drawing on two contrasting leadership perspectives; that is transformational leadership and leader-member exchange (LMX), and the research on open-mindedness norms. Specifically, we argue why transformational leadership is related to knowledge creation, and also theorise how openmindedness norms and LMX quality serve as underlying mechanisms to underpin the effect of transformational leadership on knowledge creation. We conclude with a discussion of implications of the model for theory and practice, and also suggest potential avenues for future research.
\end{abstract}

(146 words)

Keywords: transformational leadership; leader-member exchange (LMX); open-mindedness norms; knowledge creation; teams

Recently there has been an upsurge of interest in exploring factors that influence knowledge creation in organisations (see McFadyen \& Cannella, Jr 2004; Un \& CuervoCazurra 2004). This pervasive research interest results from the fact that knowledge creation is characterized as a product and function of social capital that is critical to organizational development and effectiveness (e.g., Amabile 1998). A review of research demonstrates that leadership has been regarded as one of the most important factors to determine organisational learning and creativity (e.g., Berson, Nemanich, Waldman, Galvin \& Keller 2006; Bryant 2003; Shin \& Zhou 2003, 2007). Little research attention, however, has been given to further 
our understanding of the implications of leadership for effective knowledge-creation and its underlying processes (e.g., Jung, Chow \& Wu 2003). We know little about the type of leadership that facilitates knowledge creation, and the mechanisms through which such leadership operates effectively.

Tsoukas (1996) and Berson et al. (2006) proposed that organisations are characterised as distributed knowledge systems, meaning that they are composed of knowledge that is embodied in individuals' relationships and their social interactions in a larger social collective network. According to this perspective, the process of knowledge creation is based on the generation of ideas through the assimilation of previously disconnected component knowledge into integrated knowledge among individuals at work (Tenkasi \& Boland 1996). Theoretically, when individuals communicate and interact as members of a team, they can play a boundary-spanning role by assimilating diverse knowledge. However, the knowledge creation process is often hampered by lack of interpersonal trust and lack of explicit knowledge-sharing routines (Burt 2001, 2003). With respect to this, transformational leadership has been identified as an effective approach to facilitate knowledge creation processes because such leadership draws on the assumption that certain leader behaviours can arouse followers to a higher level of thinking, enhance commitment to a well-articulated vision and inspire followers to develop new ways of solving problems (Bass 1985, 1998; Avolio \& Bass 1994).

According to Bass $(1985,1998)$ the basic premise of transformational leadership is that the motivational effects of transformational leadership are transmitted through follower perception and reactions to the leader. This suggests that there are underlying psychological processes to underpin why and how individual effectiveness can be facilitated and enhanced by the effects of transformational leadership. Several studies have shown that transformational leadership effects are explained by how followers come to feel about 
themselves or their group in terms of self-efficacy and group potency (e.g., Shamir, House \& Arthur 1993; Sosik, Avolio \& Kahai 1997; Bono \& Judge 2003). Based on this notion, we propose two psychological mechanisms; that is open-mindedness norms and leader-member exchange (LMX) to explain how transformational leadership effects are transmitted through follower response to the leader in knowledge creation processes.

In this article, we attempt to advance the research on leadership and knowledge creation in several ways. First, we respond to the call by Sosik (1997) and Bryant (2003) to understand the role of transformational leadership in the process of knowledge creation. To achieve this, we develop arguments explaining the relationship between the characteristics of transformational leadership and knowledge creation in teams. Second, we propose that openmindedness norms and LMX are psychological process variables that mediate the relationship between transformational leadership and knowledge creation. This addresses the call by Jung (2001) and Jung et al. (2003) to identify underlying process variables linking transformational leadership and knowledge creation or creativity. Finally, our article also informs the extant literature about the relative importance of the psychological mechanisms in the leadershipknowledge-creation process. Specifically, we suggest that future research should examine the competing effects of open-mindedness norms and LMX in order to further understand which mechanism leaders should adopt to enhance the effectiveness of knowledge creation in teams.

\section{THEORETICAL MODEL AND PROPOSITION DEVELOPMENT}

Figure 1 depicts a model in which we propose open-mindedness norms and LMX relationships as mediators linking the relationship between transformational leadership and knowledge creation. There are seven propositions illuminating the theoretical logic of each of the proposed relationships between the variables in the model. The propositions were developed based on the mediation procedures outlined by Baron and Kenny (1986) including 
the following steps: 1) Independent variable (transformational leadership) needs to relate to outcome (knowledge creation) - P1, 2) Independent variable ( transformational leadership) needs to relate to mediators (open-mindedness norms and LMX relationships) - P2 and P3, 3) Both mediators (open-mindedness norms and LMX relationships) need to relate to outcome (knowledge creation) - P4 and P6, and 4) The effect of independent variable ( transformational leadership) on outcome (knowledge creation) will reduce when mediators (open-mindedness norms and LMX relationships) are included as part of the test. Given this is a theoretical article, we only focus on discussing how open-mindedness norms and LMX mediate the leadership- knowledge-creation relationship for P5 and P7 instead of testing the mediating effect.

FIGURE1. A Theoretical Model of Transformational Leadership and Knowledge Creation

Antecedent

Mediators

P5 is the mediating path of Open-mindedness Norms

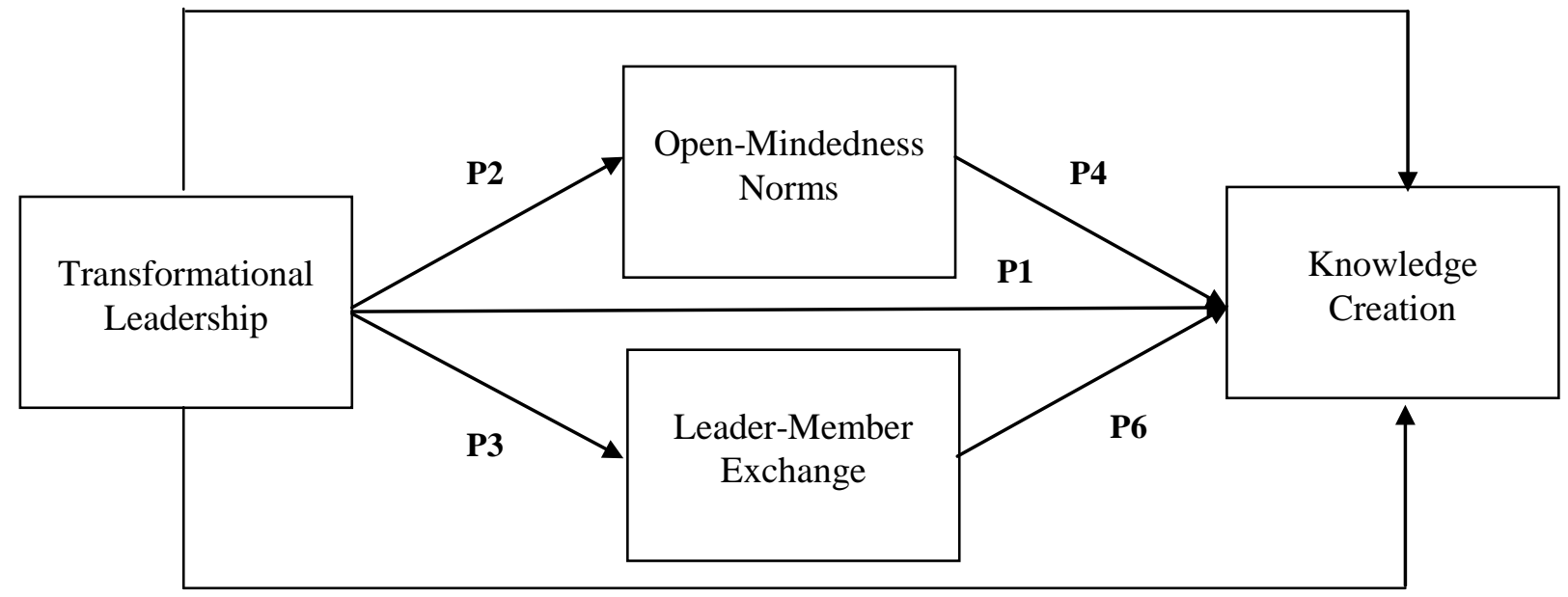

P7 is the mediating path of Leader-member Exchange
Outcome

Knowledge

Creation

In the following section, we provide the theoretical rationale underlying our model development and present arguments that specify the role of each variable and its relationships in the model. We begin by discussing the extant research concerning the relationship between 
the characteristics of transformational leadership and knowledge creation. Following this, we discuss how transformational leadership relates to the mediators - open-mindedness norms and LMX relationships, and also outline our reasoning to justify how the mediators influence the relationship between transformational leadership and knowledge creation within the model.

\section{Transformational Leadership and Knowledge Creation}

One of the most difficult issues challenging researchers in the knowledge creation literature is how to best define and conceptualise knowledge creation (Styhre, Roth \& Ingelgard 2002; Parent, Gallupe, Salisbury \& Handelman 2002). It can be defined as a process, output and outcome (Mitchell \& Nicholas 2006). As a process, knowledge creation comprises the initiatives and activities undertaken towards the generation of knowledge, new ideas and objects. As an output, knowledge creation is the constructive change in subjective knowing, assessed as significantly different from extant knowledge, which provides a conceptual basis for knowledge creation outcomes. As an outcome, knowledge creation is the generation of value-adding objects. Similar to Johnson (2002) and Parent et al. (2000), we adopt the output-based approach to define knowledge creation as an immediate product of the knowledge creation process, specifically the development of new ideas that reflect a significant elaboration or enrichment of existing knowledge for the purpose of this article.

The existing research suggests that knowledge creation has strong implications for the development of organisational competitive advantage. For example, several researchers as Nonaka, and Takeuchi (1996), Fong (2003) and Ravichandran and Rai (2003) indicate that individuals’ abilities to generate new knowledge constitutes increasingly rare and socially complex capabilities that contribute to competitive advantage of an organization over its competitors. This notion is supported by other research findings suggesting that successful 
knowledge creation and implementation will help improve the efficiency and effectiveness of organizational operations (Lippman \& Rumelt 1982; Lado \& Zhang 1998; Coff 2003).

Although the findings of these studies are important and encouraging, researchers noted that there is little understanding of what factors predict knowledge creation from an individuallevel perspective because the existing research has primarily focused on exploring factors for knowledge creation at the organizational level (Fong 2003; Coff 2003).

Based on the characteristics of knowledge creation, we suggest that transformational leadership influences how individuals approach, interpret, and establish knowledge creation at work. According to Bass (1995, 1998), transformational leadership has four dimensions that include idealised influence, inspirational motivation, intellectual stimulation and individualised consideration. Idealised influence is the degree to which leaders act in charismatic means to facilitate followers’ emotional attachment and psychological identification with them (Bass 1985). Inspirational motivation is the degree to which leaders articulate compelling vision and mission that appeal to their followers (Bass 1985). Intellectual stimulation is the degree to which leaders challenge existing assumptions of doing things and stimulate new ideas and innovative approaches for problem solving (Bass 1995). Individualised consideration is the degree to which leaders provide personal attention and encouragement, concern and support for followers’ self-development (Bass 1985).

We therefore argue that the characteristics of transformational leadership facilitate effective knowledge-creation processes in several ways. First, leaders who display transformational leadership are able to stimulate social identification of followers through articulating a compelling vision about the importance and value in teams (Bass 1985, 1998). Research indicates that mitigating the effects of social categorisation can increase individuals' commitment to a shared vision of knowledge creation because the process of social categorisation is associated with the emergence of distrust, conflict and information- 
withholding among team members (Dougherty 1992; Nonaka \& Konno 1998). Hence, we argue that by articulating a compelling vision of knowledge creation, leaders can enhance followers' perceptions of intra-team similarity to a collective perception. This has been found to lessen the effects of subjective biases and personal stereotypes of individual differences (Sethi, Smith \& Park 2001). Followers would tend to appreciate the benefits of individual differentiation more and perceive the unique knowledge, skills, experiences and abilities of other members as important because they contribute to a larger collective process of knowledge creation in organisations.

Second, when leaders express confidence in followers' capabilities and recognize their effort in knowledge creation, the followers' self-esteem and self-worth will be increased. This is because creating new ideas to enrich existing knowledge is very difficult and followers often experience failure and negative emotions such as disappointment, frustration and even anger during the processes (Sosik 1997; Jung 2001). Some followers may even doubt their capabilities and potential to further the knowledge creation process. In this regard, we argue that leaders who provide emotional uplift to their followers will encourage and comfort them, so the followers can continue to keep up their effort in developing new knowledge for organisational effectiveness.

Third, intellectual stimulation of transformational leaders has implications for follower knowledge creation. The theoretical underpinning is that leaders displaying intellectual stimulation always encourage their followers to think creatively in order to explore new ways of doing things (Bass 1985; Avolio 1999). Specifically, the leaders provide constructive feedback to their followers and also act as role models to demonstrate how to think creatively about complex problems and existing practice. This helps followers overcome convergent pressure that has been identified as acting as ‘idea boundaries’ by which new knowledge creation is likely to be constrained, pressing individuals to develop ideas that are perceived as 
legitimate in their team (Teece 1998). We also argue that intellectual stimulation of transformational leadership can enhance followers’ novel interpretations of existing information and strengthen the process of debating differing ideas within a team. Shin and Zhou (2003) and Jung (2001) found that transformational leadership has a positive relationship with creative behaviour and idea generation. Evidence further supports the role of transformational leadership in facilitating divergent thinking in teams (Jung \& Avolio 2000), which has also been linked to knowledge creation (DeDreu \& West 2001).

Finally, the link between transformational leadership and knowledge creation is based on an assumption that knowledge is created through an interactive process of drawing out, analysing and integrating knowledge (Bhatt 2000; Sosik 1997). Research, however, indicates that there are significant barriers to the interactive process supporting knowledge sharing and integration (Szulanski 1996), many of which are related to poor interpersonal relations and lack of trust. In this respect, transformational leadership has been effective for the development of strong interpersonal relationships (Wang et al. 2005). For example, Howell and Hall-Merenda (1999) found that transformational leadership has a strong positive relationship with high-quality exchange relationship between supervisors and subordinates because mutual respect, trust and concern are facilitated by the leadership characteristics. Therefore, we suggest that transformational leadership is conducive to increased knowledge creation, and we propose:

Proposition 1: Transformational leadership is positively associated with knowledge creation.

\section{Transformational Leadership and Open-Mindedness Norms}

Open-mindedness norms are defined as beliefs relating to the way in which individuals approach the views and knowledge of others in their group, and include freedom to express 
alternative views and perspectives, and willingness to recognise the value of others' knowledge (Tjosvold \& Poon 1998; Tjosvold \& Sun 2003). Building upon the existing research on transformational leadership, we argue that each leadership characteristic has a potential impact on knowledge creation through open-mindedness norms. As Tjosvold and Poon (1998) have noted, creating and promoting open-mindedness norms enables followers to understand that they are not in isolation from other coworkers in teams, because the norms would affect the expectations of, and how they interpret their experiences of transformational leadership. This in turn affects their attitudes and behaviours towards knowledge creation in teams. Hence, leaders who display transformational leadership will create and make use of the established norms as a mechanism to guide and inspire their followers about how they can support the norms (Schaubroeck, Lam \& Cha 2007). The theoretical support for the link between transformational leadership and open-mindedness norms is based on leaders' capabilities of articulating the value of the norms and supporting them.

Bass (1985) posited that transformational leadership encompasses intellectual stimulation which involves questioning basic assumptions, challenging the status quo and soliciting followers' ideas. We argue that leaders who exhibit intellectual stimulation will seek new perspectives and ways to perform tasks that enhance their followers' perceptions of team value such as open-mindedness norms. Research reveals that stimulating novel approaches increases the likelihood of group norms that promote open-minded orientation for seeking alternatives from different perspectives (Eisenhardt, Kahwajy \& Bourgeois 1997; Okhuysen \& Eisenhardt 2002). One interpretation of these findings is that processes which explicitly encourage questioning and challenging of accepted ideas leads to the development of a norm in which members believe that alternative views should be expressed openly, attended to and considered for integration into the final solution. This argument is also supported by a recent study, reinforcing the role of leaders in shaping formal team norms 
through expectations and appropriate attitude as well as behaviour (Taggar \& Elleis 2007). Hence, we argue that when leaders act as role models in setting up standards, followers are guided to interpret what is appropriate to do with the norms of open-mindedness in a team because such followers experience congruence between the leaders' behaviour and the norms.

We also expected that leaders who are able to articulate the value such as openmindedness norms will lead followers to view the norms as significant and instrumental. Such followers would internalise the norms and take pride in being part of the team to support its norms for being more open and receptive to individuals’ ideas and suggestions. Research has shown that transformational leadership is effective in influencing followers' perceptions of organizational interests over their own personal welfare (Wang et al. 2005; Bass 1985). By making the norms inspirational and symbolic, we argue that leaders can build collective identification of their followers via linking their self-interest to the norms. Followers therefore feel motivated to adjust their attitude and behaviour towards the expectations of the norms.

Finally, there is evidence suggesting that followers of leaders who engage in coaching and mentoring believe that such followers are more likely to embrace team norms and values (Schaubroeck et al. 2007). We believe that this evidence can be interpreted in that followers experience more personal concern and support about their perceptions and reactions to team norms when their leaders display individualized consideration. The two streams of research on transformational leadership and open-mindedness norms lead to the development of the following proposition.

Proposition 2: Transformation leadership is positively related to open-mindedness norms. 


\section{Transformational Leadership and Leader-Member Exchange (LMX)}

Leader-member exchange theory focuses on the way leaders and subordinates form unique relationships over time as they influence each other and negotiate their roles in the relationship (Graen \& Uhl-Bien 1995). According to the theory, the relationship between supervisors and subordinates is a reciprocal exchange and continuous role making process, influenced by the expectations of both leaders and subordinates (Dansereau et al. 1975; Graen \& Uhl-Bien 1995). LMX theory also suggests that leaders have difficulty forming equal quality of relationship with every member in a workgroup because of their limited resources, time, and abilities. A high-quality LMX relationship is characterised by mutual trust, respect, and influence that go beyond a formal employment contract (Gerstner \& Day 1997), whereas a low-quality relationship develops based on the terms and conditions of a formal employment contract (Gerstner \& Day 1997).

Although transformational leadership and LMX seem to be conceptually overlapping, they are two separate constructs theoretically. Transformational leadership emphasizes a set of unique leader behaviours directed towards followers based on self-concept motivational theory (Shamir et al. 1993), and LMX focuses on dyadic interpersonal relationships that draw on social exchanges and role-making processes (Blau 1964; Katz \& Kahn 1978). Hence, we argue that the behaviours of transformational leadership determine how followers develop and maintain the quality of LMX relationships with their leaders. Specifically, when leaders provide individualized consideration to their followers, their LMX relationships are strengthened. Such followers feel a great sense of obligation to the leaders because their leaders often act as mentors to coach them individually, and the leaders are also willing to accommodate their needs and wants (Bass 1985, 1998). The leaders also take proactive roles in nurturing the talents and potentials of their followers in different situations (Bass, 1985; Avolio 1999). Followers experiencing the individualized consideration behaviour of their 
leaders will characterise their LMX relationships as invaluable because they perceive their leaders to be reliable and trustworthy in exchange processes and the leaders also provide them with work-related benefits and organisational resources beyond their expectations (Wang et al. 2005). Deluga (1992: 245) also noted that "transformational leaders may help foster the development of high-quality relationships and a sense of common fate with individual subordinates; while in a social exchange process, subordinates strengthen and encourage the leader”. The results of Deluga's study show that individualised consideration and charisma of transformational leadership were found to have strong positive relationships with LMX.

In addition, Wang and colleagues (2005) conducted the most comprehensive study to investigate the relationship between transformational leadership and LMX relationship. They examined the psychometric properties of transformational leadership and LMX to distinguish their conceptual similarities, and to test the extent to which the relationship between the variables is existed. They conducted confirmatory factor analyses by including the latent constructs measuring the dimensions of transformational leadership and LMX. Structural equation modelling results of their study revealed that six dimensions of transformational leadership and four dimensions of LMX were conceptually distinct but empirically related to each other. The items measuring transformational leadership and LMX were loaded onto their respective dimensions and their factor loadings were higher than .40. To further demonstrate the discriminant validity, Wang and his colleagues compared the variance shared by each construct and its measures with the variance shared by both constructs. Results indicated that the variance-extracted estimates for transformational leadership and LMX were .68 and .55 which were larger than .50 and smaller than the squared correlation between these two latent constructs (.64). These results meet the benchmark of the test outlined by Fornell and Larcker (1981). 
Wang et al.’s (2005) results also supported a positive association between overall transformational leadership and LMX. These results corroborated with others reported in previous studies by Deluga (1992) and Howell \& Hall-Merenda (1999), indicating that transformational leadership has a strong positive impact on LMX. Based on the above theoretical discussion and empirical findings, we propose:

Proposition 3: Transformational leadership is positively related to LMX.

\section{Open-Mindedness Norms and Knowledge Creation}

Open-mindedness norms have been proposed to facilitate co-operative interaction patterns even in high conflict processes (Tjosvold \& Poon 1998). Researchers have found that open-minded interactions lead to increased curiosity and information seeking when group members are confronted with an opposing position and alterative ideas (Tjosvold \& Morishima 1999; Tjosvold \& Sun 2003). Individuals with an open-minded approach have been found to be more likely to attend to opposing ideas and make an effort to understand confronting perspectives. By promoting frequent communications, discussions and task contributions, open-mindedness norms facilitate the expression of different viewpoints and exchange of information, and foster a willingness to engage in debate among group members (Chen \& Tjosvold 2002). The extent to which group members use alternative or opposing

ideas positively influences its ability to resist conformity pressures, increases the likelihood of divergent thinking, and facilitates the application of different perspectives to codified knowledge, all of which are important contributions to knowledge creation (Brown \& Duguid 2001; DeDreu \& West 2001).

In addition, while the majority of research undertaken on open-mindedness norms has focused on its implications in the conflict and negotiation context, little of this has found a 
strong link between open-mindedness and information sharing and enhanced shared understanding in teams (Tjosvold \& Morishima 1999; Tjosvold \& Sun 2003). As a result, we respond to the call by providing a theoretical conjecture for the link between openmindedness norms and knowledge creation. We assert that open-mindedness norms exert their impacts on knowledge creation because such norms help determine how individuals understand, accept and think through the ideas expressed and shared by other members, and attempt to utilise the ideas for their own new knowledge creation. The open-mindedness norms serve as social cues that guide team members to believe and behave consistently with the norms so they are more willing to suggest their ideas and develop new ways of thinking that would result in increased likelihood of knowledge creation in teams. Based on the above discussion, we propose

Proposition 4: Open-mindedness norms have a positive relationship with knowledge creation.

\section{The Mediating Role of Open-Mindedness Norms}

Individuals’ perceptions of open-mindedness norms can be argued as an intermediate mechanism linking the relationship between transformational leadership and knowledge creation. We argue that individuals think divergently and integrate previously disconnected ideas when they have freedom to express their ideas and when they actively understand and utilise the best of each others’ ideas (Mitchell \& Nicholas 2006). In this regard, leaders facilitate the emergence of open-mindedness norms by displaying charismatic qualities, encouraging intellectual development and paying individual attention to followers' needs that in turn facilitate knowledge creation processes (Bass 1985; Bryant 2003; Jung 2001). These transformational leader behaviours strengthen the open-mindedness norms, which in turn 
influence followers’ perceptions and experiences about the importance of knowledge creation, and behaviours that are likely to lead to knowledge creation in their team.

As noted previously, open-mindedness norms represent a shared perception and a collective sharing of what leaders and other coworkers are expected to do in order to enhance knowledge creation. By encouraging the development of open-mindedness norms, we argue that leaders act to increase the likelihood of knowledge creation, guiding their followers to accept and internalise the norms to behave collectively. As the leaders continue foster the norms of open-mindedness, team members are more likely to express different and alternate ideas, and actively debate and utilise these ideas for knowledge creation (Tjosvold \& Sun 2003). To the extent that there is a high level of intellectual interaction and discussion among team members, research indicates a link to cognitive enhancement and cross-fertilisation of perspectives both of which are connected to knowledge creation (Mumford \& Gustafson 1988; Pearce \& Ravlin 2000).

Based on the preceding discussion and reported findings, we suggest that openmindedness norms are likely to mediate the relationship between transformational leadership and knowledge creation because we believe that the effectiveness of knowledge creation is dependent on how leaders set and maintain the open-mindedness norms. Once the norms have been established, the leaders will support the norms by displaying appropriate leader behaviours that are consistent with the norms. Such norms are perceived by followers as important culture to reflect how their leaders and other coworkers value and recognise new knowledge being created through collaboration in teams. Thus, we propose:

Proposition 5: Transformational leadership has a positive relationship with knowledge creation through the mediating effect of open-mindedness norms. 


\section{Leader-Member Exchange and Knowledge Creation}

The effect of LMX on knowledge creation is premised on the idea that LMX between a leader and follower is an interpersonal exchange relationship that constitutes social capital enacted in a larger social system in organisations (Graen \& Uhl-Bien 1995; Sparrowe \& Liden 1997; McFadyen \& Cannella, Jr 2004). Researchers such as Bourdieu (1996) and Coleman (1998) have posited that resources and information are embedded and explored within work relationships. Social capital's positive impact on knowledge creation is based on the understanding that it enhances both knowledge availability and the knowledge sharing process. Findings indicate that knowledge creation has had a strong positive link to the amount, strength and distance of knowledge exchange relationships (McFadyen, \& Cannella Jr 2004). Of particular relevance to LMX effect is the relational dimension of social capital, which refers to assets created and leveraged through interpersonal relationships - the 'bonds' that influence the behaviour of both parties within relationships (McFadyen \& Cannella Jr 2004; Graen \& Uhl-Bien 1995). By establishing a positive social exchange relationship with a follower, we argue that leaders provide the follower access to knowledge embedded in the leader's broader network.

According to Nahapiet and Ghoshal (1998), social capital and knowledge creation have a positive relationship because social capital determines the combine-and-exchange process and also makes the resources easily accessible. As such, the quality of LMX relationship is important in that it can facilitate the knowledge creation process because knowledge is combined and shared within the quality of exchange relationships between leaders, followers and coworkers (Graen 2006). The quality of exchange relationships determines how willing the involved parties are to share resources, information and ideas to create new knowledge. Hence, the quality of LMX relationship serves as a foundation to develop effective knowledge-creation processes in teams. A recent study by Tse, Dasborough and Ashkanasy 
(2008) found that the quality of LMX relationships between supervisors and subordinates positively influences the lateral interpersonal relationship development among team members. If the supervisors and subordinates have high-quality exchange relationships, subordinates are then more likely to develop good exchange relationships with other team members. Tse et al.’s (2008) findings are consistent with the results reported by Sheorny and Green (2002) who found that the quality of LMX relationships between a leader and a follower has a positive relationship with coworkers exchange relationships. The findings of both studies suggest that the quality of LMX relationships will determine how the individual coworkers respond to relationship development with other team members. Through frequent communication and interactions, individuals are able to access and leverage work-related benefits, important information and organisational resources embedded in exchange relationships for desirable work outcomes such as knowledge creation (Graen 2006; Basu \& Green 1997). The preceding discussion and empirical findings lead to the development of the following proposition:

Proposition 6: LMX quality has a positive relationship with knowledge creation.

\section{The Mediating Role of Leader-Member Exchange}

With respect to the mediating role of LMX, we propose that transformational leadership enhances LMX relationships that in turn influence knowledge creation in teams. As discussed earlier, transformational leadership nourishes LMX through attending to followers' needs and wants and focusing on their self-development and personal improvement (Wang et al 2005). This leader behaviour is perceived by followers as a strong intrinsic motivation to develop and maintain high-quality LMX relationships with their leaders because the relationships can be characterised as an emotional link and unstated mutual expectation for reciprocity (Blau, 
1964; Basu \& Green 1997). Leaders and followers in high-quality LMX relationships create reciprocal mutual relationships to satisfy the expectations of each other so that both parties will continue to invest their time and resources for maintaining the relationships (Graen \& Uhl-Bien, 1995). When the leaders display individualised consideration focusing on followers' personal growth and self development, the followers are also likely to experience a sense of satisfaction and achievement, so they elevate their commitment to knowledge creation in return for the quality of the relationships.

In addition, we argue that transformational leadership can create and communicate a shared identity or value of knowledge creation in the role making process of LMX exchanges with their followers. This can be achieved by evoking followers' self-concept in recognition that they share similar values or personal identification with the leader (Kark Shamir \& Chen 2003; Tse 2008). In this regard, Shamir et al. (1993) suggest that role modelling is perceived as a psychological process by which transformational leadership influences followers for performing beyond their initial expectation. Once followers' self-concept has been provoked, the followers would strive to change their beliefs, behaviours and feelings according to those of their leader (Kark et al. 2003; Tse 2008). This suggests that followers will internalise the importance of knowledge creation via the high-quality LMX relationships with their leaders. The high-quality LMX exchanges serve as contexts in which followers experience strong emotional attachment and posses similar values as team members who have similar quality of relationships with their leaders (Wang et al. 2005; Tse et al. 2008).

In line with the above discussion, we suggest that the quality of LMX relationship serves as a mediator linking the relationship between transformational leadership and knowledge creation because the quality of the relationship represents both intrinsic (emotional bonding) and extrinsic (work-related benefits) means of motivation. We argue that the perceived resource support and emotional concern facilitated by transformational leadership 
are personalised through the quality of LMX relationships that result in increased knowledge creation in teams. Therefore, we propose:

Proposition 7: Transformational leadership has a positive relationship with knowledge creation through the mediating effect of LMX relationships.

\section{Relative Importance of Open-Mindedness Norms and Leader-Member Exchange}

With respect the relative importance of the open-mindedness norms and LMX

relationship as mediators influencing the relationship between transformational leadership and knowledge creation, the existing literature suggests a competing view on the mediating effects of open-mindedness and LMX relationships in the underlying process. The premise relating to the role of open-mindedness norms is that leaders can spend less time and resources to develop and facilitate the emergence of open-mindedness norms by articulating such norms as part of the team's shared vision. The norms will shape followers' attitudes and actions towards contributing their effort to knowledge creation through expression of ideas, thinking and experiences (Tjosvold et al. 1999). We argue that the norms are similar to visions or missions that leaders make compelling in order to maximise individual potential for collective goals.

In contrast, the quality of LMX emphasises a one-to-one reciprocal exchange relationship and leaders have less time, resources and energy to develop equal quality of relationships with all followers in teams (Graen 1976). According to Graen and Uhl-Bien (1995), a dyadic LMX relationship is formed through three developmental stages, namely, "stranger”, “acquaintance” and "partner” that reflect how the process of economic and social exchanges occurs. The success of each developmental stage is contingent on how many members have dyadic relationships with leaders at each time. Hence, the size of teams seems 
to be a potential factor in determining which mechanism leaders should adopt to better manage their resources for effective knowledge-creation. More recently, however, Sparrowe and Liden (2005) and Cole, Schaninger and Harris (2002) suggest that interpersonal relationships between leaders, subordinates, and coworkers constitute an interconnected social system that operates in teams and organisations. This notion suggests that the quality of LMX relationships can be a driving force to facilitate the social system in which team members will exchange information, share work-related resources and provide emotional support to each other (Graen 2006). The social system would help manifest the effect of transformational leadership on knowledge creation and facilitate a collective effort.

On this basis, the existing literature appears to suggest that both open-mindedness norms and LMX relationships are equally important and each plays an important role in the knowledge creation process. Therefore, we suggest that leaders can rely on open-mindedness norms to influence followers' perceptions of enhanced knowledge creation if the team size is relatively large, whereas leaders can develop high-quality LMX relationships with followers to facilitate knowledge creation if the team size is relatively small. We acknowledge that this suggestion may be speculative because no empirical studies have been conducted to test the relative effect of the mediators in the relationship between transformational leadership and knowledge creation, and whether team size will moderate the relationships between transformational leadership, open-mindedness norms and LMX relationships. Hence, rather than developing a conclusive interaction proposition, we encourage researchers to take team size into consideration when they attempt to examine its possible moderation effects in future empirical research. 


\section{Scope of the Model}

It is important to acknowledge that the relationship between transformational leadership and knowledge creation in teams can be affected by other potential mediating variables which have not been specified and included in this model. These process variables consist of trust, satisfaction, and personal identification and they are regarded as followers' attitudes towards leaders that can exert moderate positive impacts on the relationships between the variables in the model (e.g., Kark et al. 2003; Pillai, Schreisheim \& Williams, 1999; Podsakoff, MacKenzie, Moorman \& Fetter 1990; Piccolo \& Colquitt 2006). For example, Kark and colleagues (2003) found that followers’ personal identification with leaders and social identification with teams are important in influencing how they perceive and react to the transformational leader behaviours. Similarly, Podsakoff et al. (1999) also revealed that followers' willingness to trust the leaders will determine followers' attitudes towards the implications of transformational leadership. The findings of these studies suggest that followers' characteristics play a role in leadership processes for followers' work attitudes and behaviour. While these variables are important, they are outside the scope of the proposed relationships in the current model which focuses specifically on knowledge creation processes for parsimony. It is also arguable that there are other potential conceptualisations available for the model development. For example, leader member exchange influences transformational leadership and open-mindedness norms to enhance knowledge creation. Nonetheless, current research findings and the existing literature appear to support the present model development, rather than the alternatives. Although the variables proposed in the model are not exhaustive, it does attempt to explore the nature of transformational leadership and knowledge creation in teams. 


\section{DISCUSSION}

\section{Implications for Theory and Research}

We attempt to make three contributions to the literature on leadership and knowledge creation. First, as Peteraf and Barney (2003) and Zollo and Winter (2002) suggest, although research on knowledge creation has been extensively studied over the last decade, the relationship between leadership and knowledge creation has not been explicit and fully established. In this article, we take a proactive approach to integrate two perspectives on leadership and research on open-mindedness norms by developing a model to explain knowledge creation process in teams. Specifically, the model provides a better understanding of the effects of transformational leadership on knowledge creation. By examining the model and its proposed relationships, we believe that it will enable researchers to shed new light on this issue.

Second, our model provides insights into the role of open-mindedness norms and LMX relationships in the underlying process of transformational leadership and knowledge creation. Researchers, such as Tjosvold and Poon (1998) suggest that open-mindedness norms can constitute a supportive environment that influences individuals' perceptions of how their ideas, knowledge and experience can be shared with their team members. To date, research on open-mindedness norms has been primarily studied in the communication and conflict literature (Tjosvold \& Sun 2003). In this article, we take the initiative by exploring the role of open-minded norms in the leadership-knowledge-creation process in order to understand its potential antecedents and consequences. In addition to this, the exact nature of how dyadic exchange relationships are developed within a knowledge creation process is largely unknown in the literature. This article is among the first to address this issue by discussing how LMX links transformational leadership and knowledge creation together. We believe that transformational leadership is seen by followers as a social currency to nourish their quality of 
LMX relationships which in turn encourages their input for knowledge creation. This offers a new dimension in examining how the two contrasting perspectives on leadership can facilitate knowledge creation simultaneously.

Third, we discuss the relative importance of open-mindedness norms and LMX as underlying mechanisms to determine what leaders should rely on to optimise individuals' abilities and experience for knowledge creation in teams. Although we were unable to test the relative importance of the underlying mechanisms in the relationship, we argue that both open-mindedness norms and LMX relationships are equally important in the leadershipknowledge-creation process depending on how much time and resources the leaders have within the process. This notion helps leaders develop strategies to leverage their time and resources in promoting effective knowledge-creation through developing strong openmindedness norms or making an effort to form high-quality relationships with all team members.

\section{Implications for Practice}

Besides the theoretical contributions, we believe that the proposed model of leadership and knowledge creation has two practical implications. The model builds upon the premise that transformational leadership has a significant impact on individual perceptions of knowledge creation through open-mindedness norms. Previous research indicates a number of factors that increase the likelihood of team open-minded norms. These antecedents include techniques such as the perception of co-operative goals (Tjosvold \& Poon 1998) and the use of interventions such as Devil’s Advocacy and Dialectical Inquiry (Okhuysen and Eisenhardt 2002). This model implies that leaders could benefit from including relatively accessible techniques such as these into their leadership approach, as well as directly encouraging the 
development of open-minded norms through explicit statements, modelling and reward strategies.

Another practical implication is related to the idea of LMX quality as an underlying mechanism of transformational leadership and knowledge creation. It appears to be essential that leaders learn how to develop high-quality LMX relationships with their followers by exhibiting transformational leadership in training programs. Effective leadership training programs for managers are needed to reinforce the importance and techniques of transformational leadership and relationship development with team members. Such programs can be specifically designed to educate managers to better exhibit transformational leader behaviours and develop effective LMX relationships over time. For example, programs can be provided to teach managers how they can help a new employee fit into the team so that s/he would not feel like a 'stranger', especially when the employee begins to develop relationships with the manager and other coworkers. Moreover, programs should show managers how, by developing high-quality LMX relationships, they can articulate the importance of effective work relationships within workgroups in order to maximise individual potential for knowledge creation (Bauer \& Green 1996; Bauer et al. 2006).

\section{Research Limitations}

Although this research makes several important contributions, this article has some limitations that should be noted. First, we were unable to test the proposed relationships in the current model and cannot provide empirical evidence to confirm the relative importance of the mediating role of open-mindedness norms and LMX in the relationship between transformational leadership and knowledge creation. This is particularly important because the existing research suggests a competing view on the role of the mediators. Without being able to test the model, we cannot eliminate alternative conceptualisations of the model. 
Second, it is arguable that there are other potential variables that may be included in the model. The transformational leadership literature suggests that personal identification with leaders, collective identification, trust, and job satisfaction can be conceptualised as additional psychological mechanisms that mediate the relationship between transformational leadership and knowledge creation. Although we argued earlier that these variables are important, they are outside the scope of the current model. We suggest some of the variables should be included as mediators in the model for future investigation

\section{Future Research Directions}

With respect to the proposed relationships in the model, we strongly encourage future researchers to test them using structural equation modelling (SEM) in order to estimate each path in the model and assess its overall model fit as compared to alternative models. The reason is that SEM is a useful analysis technique to generate different models for comparison and determine the model to which the data are best fitted. The model comparisons will help eliminate other possible explanations of the relationships among transformational leadership, open-mindedness norms, LMX and knowledge creation, thereby providing empirical support for the role of transformational leadership in knowledge creation processes.

Future research should also examine whether the relative importance of openmindedness norms and LMX relationships as underlying mechanisms for knowledge creation are contingent upon the size of teams. The findings of such research would have implications for understanding which mechanism leaders should use to better manage their time and resources for effective knowledge-creation. Currently, the literature seems to suggest a competing view about the role of open-mindedness norms and LMX relationships in the relationship between transformational leadership and knowledge creation. For example, the open-mindedness norms literature suggests that leaders can spend less time and resources 
establishing the norms to facilitate knowledge creation in a team, whereas, LMX involves time and resources for building a one-to-one reciprocal exchange relationship to stimulate knowledge creation among team members (Graen \& Uhl-Bien 1995). By theorising and testing team size as a moderator in the relationships, it will identify what psychological mechanisms leaders should use to facilitate effective knowledge-creation.

\section{CONCLUSION}

This article provides insights into the role of transformational leadership in knowledge creation processes. We developed a model theorising the differential mediating effects of LMX relationships and open-mindedness norms in the relationship between transformational leadership and knowledge creation. The model suggests that both open-mindedness norms and LMX relationships are important underlying mechanisms illuminating the effectiveness of transformational leadership for knowledge creation. We conclude that managers need to form open-mindedness norms and develop dyadic interpersonal exchange relationships with followers, as well as engage in all aspects of transformational leadership in order to better leverage their time and resources for knowledge creation. We envisage that the proposed model will stimulate more research attention to exploring the theoretical and practical implications of transformational leadership for knowledge creation in organisations.

\section{REFERENCES}

Amabile T M (1988) A model of creativity and innovation in organisations, in Staw, B.M, Cummings, L.L. (Eds), Research in Organisational Behaviour, pp. 123-167, JAI Press, Greenwich, CT.

Avolio B J (1999) Full leadership development: Building the vital forces in organizations. Thousand Oaks, CA: Sage. 
Bass B M (1985) Leadership and performance beyond expectations, Free Press, New York.

Bass B M (1998) Transformational leadership: Industrial, military and educational impact. Mahwah, N. J: Lawrence Erlbaum.

Bass B M and Avolio B J (1994) Improving organizational effectiveness through transformational leadership. Thousand Oaks, CA: Sage.

Basu R and Green S G (1997) Leader-member exchange and transformational leadership: An empirical examination of innovative behaviors in leader-member dyads, Journal of Applied Social Psychology 27: 477-499.

Baron R M and Kenny D A (1986) The moderator-mediator variable distinction in social psychological research: Conceptual, strategic, and statistical considerations, Journal of Personality and Social Psychology 51: 1173-1182.

Bauer T N and Green S G (1996) Development of leader-member exchange: A longitudinal test, Academy of Management Journal 39: 1538-1567.

Bauer T N, Erdogan B, Liden R C and Wayne S J (2006) A longitudinal study of the moderating role of extraversion: Leader-member exchange, performance and turnover during new executive development, Journal of Applied Psychology 91: 298-310.

Berson Y, Nemanich L, Waldman D, Galvin B and Keller R T (2006) Leadership and organizational learning: A multiple levels perspective, The Leadership Quarterly 17: $577-594$.

Bhatt G D (2000) Information dynamics, learning and knowledge creation in organizations, The Learning Organization 7: 89-99.

Blau, P. M. (1964). Exchange and power in social life. New York: John Wiley.

Bono J E and Judge T A (2003) Self-Concordance at work: Toward understanding the motivational effects of transformational leaders, Academy of Management Journal 46: $554-571$ 
Bourdieu P (1986) The forms of capital, in Richardson J G (Eds), Handbook of theory and research for the sociology of education, pp.241-258, Greenwood, New York.

Brown J and Duguid P (2001) Knowledge and organization: A social-practice perspective, Organization Science 12: 198-213.

Bryant S E (2003) The role of transformational and transactional leadership in creating, sharing and exploiting organizational knowledge, Journal of Leadership and Organizational Studies 9: 32-44.

Burt R S (2001) Structural holes versus network closure as social capital in Lin N, Cook K and Burt R (Eds), Social capital: Theory and research, pp. 31-56, Aldine de Gruyter, New York.

Burt R S (2003) The social origin of good ideas. Unpublished manuscript. Available at http://gsbwww.uchicago.edu/fac/ronald.burt/research/.

Chen G and Tjosvold D (2002) Cooperative goals and constructive controversy for promoting innovation in student groups in China, Journal of Education for Business 78: 46-50.

Coff R (2003) The emergent knowledge-based theory of competitive advantage: An evolutionary approach to integrating economics and management, Managerial and Decision Economics 24: 245-251.

Cole M S, Schaninger W S and Harris S G (2002) The workplace social exchange network, Group and Organization Management 27: 142-167.

Dansereau F, Graen G B and Haga W J (1975) A vertical dyad linkage approach to leadership within formal organizations, Organizational Behavior and Human Performance 13: 4678.

DeDreu C and West M (2001) Minority dissent and team innovation: The importance of participation in decision-making, Journal of Applied Psychology 86: 1191-1201. 
Deluga R J (1992) The relationship of leader-member exchanges with laissez-faire, transactional and transformational leadership in Clark K E, Clark M B and Campbell D B (Eds), Impact of leadership pp.237-247, The Centre for Creative Leadership, Greensboro, NC.

Dougherty D (1992) Interpretive barriers to successful product innovation in large firms, Organization Science, 3: 179-202.

Eisenhardt K M, Kahwajy J L and Bourgeois L J (1997) Conflict and strategic choice: How top management teams disagree, California Management Review 39: 42-61.

Fong P (2003) Knowledge creation in multidisciplinary project teams: an empirical study of the processes and their dynamic interrelationships, International Journal of Project Management 21: 479-486.

Fornell C and Larcker D F (1981) Evaluating structural equations models with unobservable variables and measurement error, Journal of Marketing Research 18: 39-50.

Gerstner C R and Day D V (1997) Meta-analytic review of leader-member exchange theory: Correlates and construct issues, Journal of Applied Psychology 82: 827-844.

Graen G B (2006) To share or not share leadership: New LMX-MMX network leadership or charismatic leadership on creative projects, in Graen G B and Graen J A (Eds), Sharing network leadership, pp. 25-36. Connecticut: IAP Information Publishing.

Graen G B (1976) Role-making process within complex organizations, in Dunnette M D (Eds.), Handbook of industrial and organizational psychology, pp. 1201-1245. Chicago: Rand McNally.

Graen G B and Uhl-Bien M (1995) Relationship-based approach to leadership: Development of leader-member exchange (LMX) theory of leadership over 25 years: Applying a multi-level multi-domain perspective, The Leadership Quarterly 6: 219-247. 
Howell J M and Hall-Merenda, K E (1999) The ties that bind: The impact of leader-member exchange, transformational and transactional leadership and distance on predicting follower performance. Journal of Applied Psychology, 84: 680-694.

Johnson W H A (2002) Assessing organizational knowledge creation theory in collaborative R and D projects, International Journal of Innovation Management 6: 387-418.

Jung D (2001) Transformational and transactional leadership and their effects on creativity in groups, Creativity Research Journal 13: 185-195.

Jung D and Avolio B (2000) Opening the black box: An experimental investigation of the mediating effects of trust and value congruence on transformational and transactional leadership, Journal of Organizational Behaviour 21: 949-964.

Jung D I, Chow C and Wu A (2003) The role of transformational leadership in enhancing organizational innovation: Hypotheses and some preliminary findings, The Leadership Quarterly 14: 525-544.

Kark R, Shamir B and Chen G (2003) The two faces of transformational leadership: Empowerment and dependency, Journal of Applied Psychology 2: 246-55.

Katz D and Kahn R L (1978) The social psychology of organizations. New York: John Wiley. Lado A and Zhang M J (1998) Expert systems, knowledge development and utilization and sustained competitive advantage, Journal of Management 24: 489-509.

Lippman S A and Rumelt R P (1982) Uncertain imitability: Analysis of interfirm differences in efficiency under competition, Bell Journal of Economics 13: 418-438.

McFadyen M A and Cannella Jr A A (2004) Social capital and knowledge creation:

Diminishing returns of the number and strength of exchange relationships, Academy of Management Journal 47: 735-746. 
Mitchell R and Nicholas S (2006) Knowledge creation in groups: The value of cognitive diversity, transactive memory, and open-mindedness norms, The Electronic Journal of Knowledge Management 4: 67-74.

Mumford M D and Gustafson S B (1988) Creativity syndrome: Integration, application and innovation, Psychological Bulletin, 103: 27-43.

Nahapiet J and Ghoshal S (1998) Social capital, intellectual capital, and organisational advantages, Academy of Management Review 23: 242-266.

Nemeth C J and Nemeth-Brown B (2003) Better than individuals? The potential benefits of dissent and diversity for group creativity, in Paulus P B (Eds.), Group creativity: Innovation through collaboration, pp.63-84. London: Oxford University Press.

Nonaka I and Konno N (1998) The concept of 'Ba': Building a foundation for knowledge creation, California Management Review 40: 40-54.

Nonaka I and Takeuchi H (1996) A theory of organizational knowledge creation, International Journal of Technology Management 11: 833-846.

Okhuysen G A and Eisenhardt K M (2002) Integrating knowledge in groups: How formal interventions enable flexibility, Organization Science 13: 370-386.

Parent M, Gallupe R B, Salisbury D and Handelman J (2000) Knowledge creation in focus groups: Can group technologies help?, Information and Management 38: 47-58.

Pearce J A and Ravlin E C (2000) The design and activation of self regulating work groups. Human Relations, 40: 751-760.

Peteraf M A and Barney J (2003) Unravelling the resource-based tangle, Managerial and Decision Economics 24: 309-324.

Piccolo R F and Colquitt J A (2006) Transformational leadership and job behaviors: The mediating role of core job characteristics, Academy of Management Journal 49: 327340. 
Pillai R, Schreisheim C A and Williams E S (1999) Fairness perceptions and trust as mediators for transformational and transactional leadership: A two-sample study, Journal of Management 25: 897-933.

Podsakoff P M, MacKenzie S B, Moorman R H and Fetter R (1990) Transformational leader behavior and their effects on followers' trust in leader, satisfaction, and organizational citizenship behaviors, The Leadership Quarterly 1: 107-142.

Ravichandran, T and Rai A (2003) Structural analysis of the impact of knowledge creation and knowledge embedding on software process capability, IEEE Transactions on Engineering Management 50: 270-284.

Schaubroeck J, Lam S. K and Cha S (2007) Embracing transformational leadership: Team values and the impact of leader behavior on team performance, Journal of Applied Psychology 92: 1020-1030.

Sethi R, Smith D C and Park W C (2001) Cross-functional product development teams, creativity, and the innovativeness of new consumer products. Journal of Marketing Research 38: 73-85.

Shamir B, House R and Arthur M B (1993) The motivational effects of charismatic leadership: A self-concept based theory, Organization Science 4: 577-594.

Sherony K M and Green S G (2002) Co-worker exchange: Relationships between coworkers, leader-member exchange, and work attitudes, Journal of Applied Psychology, 87: 542548.

Sosik J J (1997) Effects of transformational leadership and anonymity on idea generation in computer-mediated groups, Group and Organization Management 22: 460-487.

Sosik J J, Avolio B J and Kahai S S (1997) Effects of leadership style and anonymity on group potency and effectiveness in a group decision support system environment, Journal of Applied Psychology 82: 89-103. 
Sparrowe R T \& Liden R C (2005) Two routes to influence: Integrating leader-member exchange and network perspectives, Administrative Science Quarterly, 50: 505-535. Sparrowe R T and Liden R C (1997) Process and structure in leader-member exchange. Academy of Management Review, 22: 522-552.

Shin S J and Zhou J (2003) Transformational Leadership, conservation and creativity: Evidence from Korea, Academy of Management Journal 46: 703-714.

Shin S J and Zhou J (2007) When is educational specialization heterogeneity related to creativity in research and development teams? Transformational leadership as a moderator, Journal of Applied Psychology 92: 1709-1721.

Styhre A, Roth J and Ingelgard A (2002) Care of others: Knowledge creation through care in professional teams, Scandinavian Journal of Management 18: 503-520.

Szulanski G (1996) Exploring internal stickiness: Impediments to the transfer of best practice within the firm, Strategic Management Journal, 17: 27-43.

Taggar S and Elleis R (2007) The role of leaders in shaping formal team norms, Leadership Quarterly 18: 105-120.

Teece D, Pisano G and Shuen A (1997) Dynamic capabilities and strategic management, Strategic Management Journal 18: 509-533.

Tenkasi RV and Boland R J (1996) Exploring knowledge diversity in knowledge intensive firms: A new role for information systems, Journal of Organizational Change Management 9: 79-91.

Tjosvold D and Morishima M (1999) Grievance resolution: Perceived goal interdependence and interaction patterns, Relations Industrielle, 54: 527-547.

Tjosvold D and Poon M (1998) Dealing with scarce resources: open-minded interaction for resolving budget conflicts, Group and organization management 23: 237-258. 
Tjosvold D and Sun H (2003) Openness among Chinese in conflict: Effects of direct discussion and warmth on integrative decision making, Journal of Applied Social Psychology 33: 1878-1897.

Tse H M (2008) Transformational leadership and performance: A social identity perspective: Paper presented at the annual meeting of Academy of Management, Los Angels, California, USA.

Tse H M, Dasborough M T and Ashkanasy N M (2008) A multilevel analysis of team climate and interpersonal exchange relationships at work, The Leadership Quarterly 19:195211.

Tsoukas H (1996) The firm as a distributed knowledge system: A constructionist approach, Strategic Management Journal 17: 11-25.

Un C A, and Cuervo-Cazurra A (2004) Strategies for knowledge creation in firms, British Journal of Management 15: 27-41.

Wang H, Law K S, Hackett R, Wang D X and Chen Z X (2005) Leader-member exchange as a mediator of the relationship between transformational leadership and followers' performance and organizational citizenship behavior, Academy of Management Journal 48: 420-432.

Zollo M and Winter S G (2002) Deliberate learning and the evolution of dynamic capabilities, Organization Science 13: 339-351. 